\title{
A mysterious growth from vulva mimicking scrotum leading to abandonment by husband
}

\author{
Sanjoy Kumar Bhattacharyya, ${ }^{1}$ Ranjan Pal, ${ }^{1}$ Hajekul Alam,,${ }^{1}$ Sohini Bhattacharya ${ }^{1}$
}

Key Words: Fibroma, Vulva, Benign

\begin{abstract}
Benign vulvar growths are rare. Initially these growths remain small and asymtomatic. Due to social stigma, young women in this stage often prefer to conceal the pathology. With considerable growth, apart from physical complaints, they might cause psychological problems of the subjects and even social withdrawal. Urgent detection and subsequent removal of the growth along with counselling is warranted to improve the patient's self-esteem.

1 North Bengal Medical College, Darjeeling, West Bengal, India
\end{abstract}

\section{Introduction}

Vulval growth in a young woman may cause emotional disturbance and often creates a social problem. ${ }^{1}$ Apart from malignant tumors, fibromas are the most common benign tumor of vulva, though these rarely occur. ${ }^{2,3}$ Different cases of vulval fibroma have been described in the literature and often lead to social withdrawal and psychological upset in the patient. ${ }^{1,4}$ This case report describes a unique complaint regarding sexual pseudo-ambiguity that arose due to the presence of a vulval fibroma.

\section{Case Report}

A 21 year old nulliparous rural Indian woman presented at a gynecological clinic with a soft, pedunculated mass with a wrinkled surface dangling from her left labia majus. This mass had been present for five years. The subject had been abandoned by her husband shortly after marriage. The mass resembled a large scrotum measuring approximately the size of a tennis ball and with a painless cystic feeling [Figure 1]. No lymph nodes were palpable in the vulval or inguinal regions. Her uterus and adnexa were normal as demonstrated by clinical and radiological examination. With a provisional diagnosis of vulval fibroma, the mass was excised along with the stalk under regional anesthesia with a good cosmetic result. A few daughter fibromas located adjacent to the main one were not excised as it entailed more extensive resection and disfigurement of external genitalia. Upon excision, cystic degeneration was noticed inside the mass [Figure-2]. Biopsy confirmed the preoperative clinical diagnosis.

Please cite this paper as: Bhattacharyya SK, Pal R, Alam H, Bhattacharya S. A mysterious growth from vulva mimicking scrotum leading to abandonment by husband. Proc Obstet Gynecol. 2012;2(4):Article 39 [ 3 p.]. Available from: http://ir.uiowa.edu/pog/. Free full text article.

Corresponding author: Sanjoy Kumar Bhattacharyya, North Bengal Medical College, Darjeeling, West Bengal, India, sanjay.krbhattacharyya@gmail.com.

This is an Open Access article distributed under the terms of the Creative Commons Attribution 3.0 Unported License (http://creativecommons.org/licenses/by/3.0), which permits unrestricted use, distribution, and reproduction in any medium, provided the original work is properly cited. 


\section{Discussion}

Vulval fibroma is a rare benign tumor arising from the deep connective tissue surrounding the introitus, especially the labia, perineal body or round ligament. ${ }^{2,3}$ Vulval fibromas have the potential to become quite large, with documented cases of fibromas hanging between knees of patients. ${ }^{2,3}$ Lipoma, inguinal hernia, vulvovaginal cysts and vulval elephantiasis are common differential diagnoses. $^{2}$ Although nonaggressive in nature, its huge size and location cause dyspareunia, emotional upset or social withdrawal of the patient as described by various investigators. ${ }^{1,4}$ Despite the different psycho-social problems that have been previously attributed to this tumor, this case report is the first to describe vulval fibroma that led to abandonment by her husband on grounds of sexual ambiguity. Due to poor socioeconomic conditions and the traditional custom in India of arranged marriage, the subject concealed the pathology before marriage. Soon after marriage when the scrotum-like genital growth was revealed, the subject was abandoned by her husband, who was illiterate with no formal schooling, due to suspicion regarding the subject's femininity.

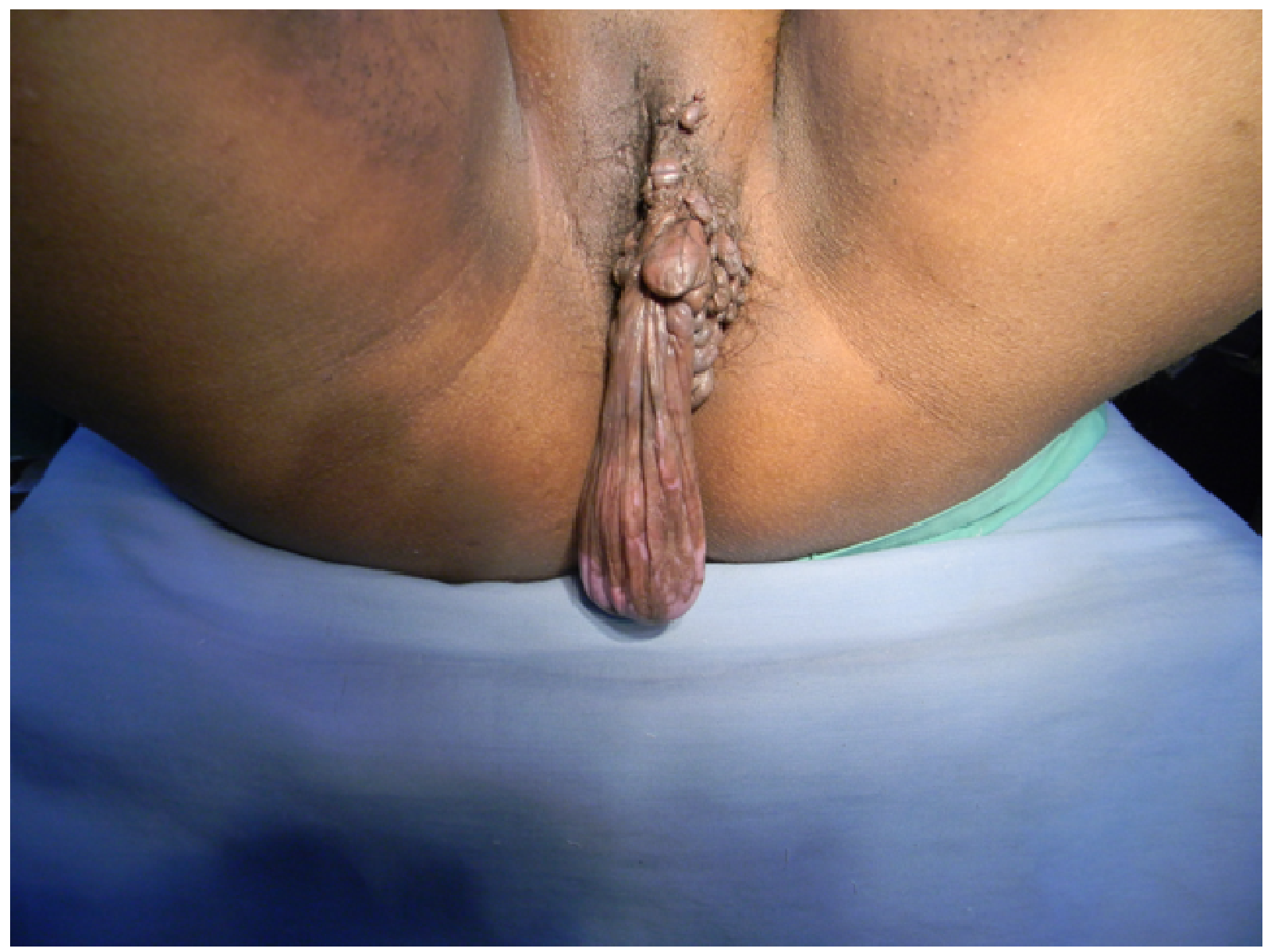

Figure 1 Vulval fibroma mimicking scrotum 


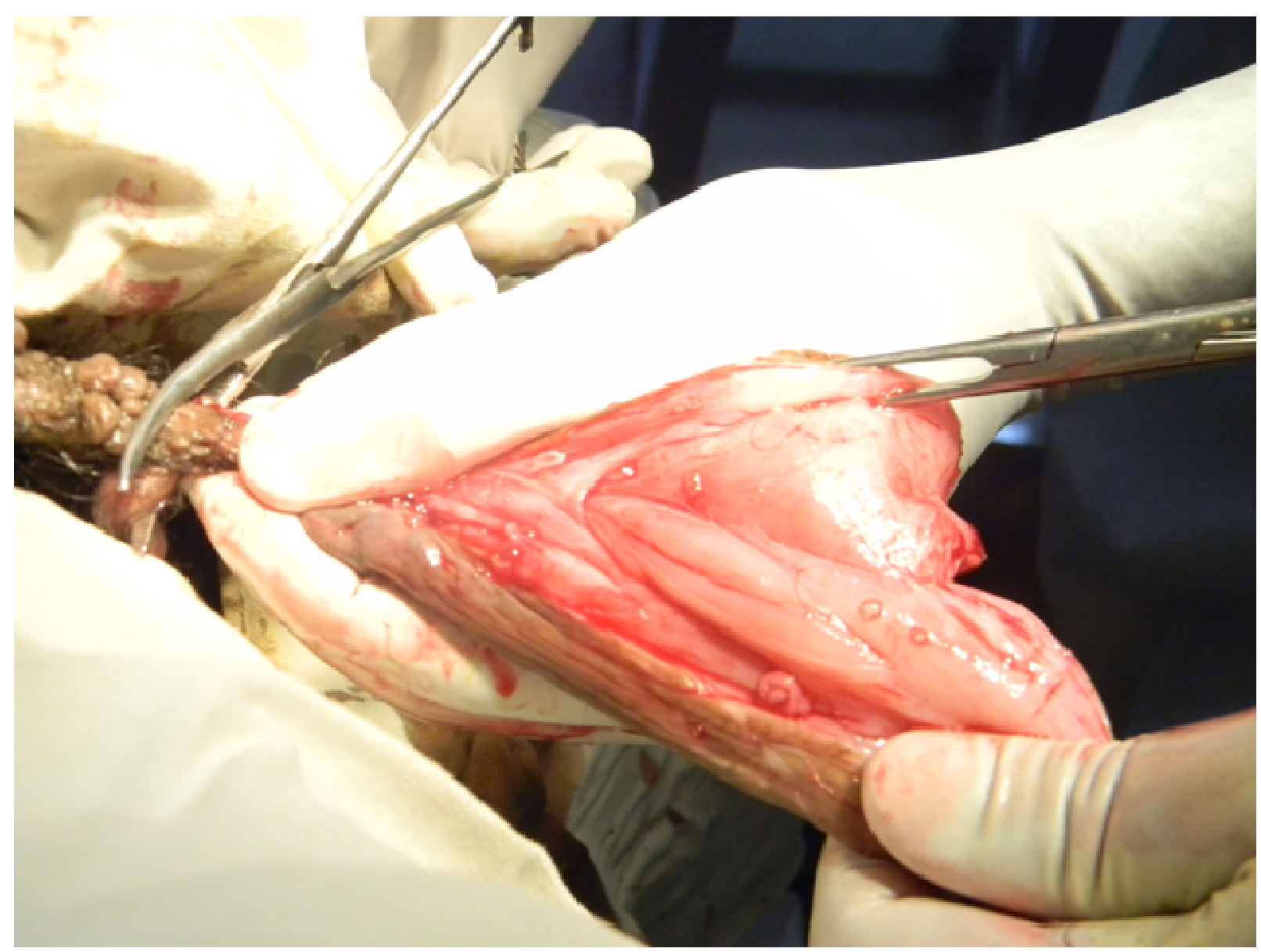

Figure 2 Cystic Degeneration noticed during excision of the vulval fibroma

The subject was depressed preoperatively but regained self-esteem following removal of the tumor. Due to the excellent cosmetic result, her husband was also motivated to reconcile. However, vulval fibroma may recur in future, especially following incomplete removal. ${ }^{4}$ We recommend proper preoperative counseling regarding this potential recurrence.

\section{References:}

1. Berlin M, Berlin S. Fibroma of the vulva: a case report. J Reprod Med. 2007 Jun;52(6):533-4. PubMed PMID: 17694973.
2. De Lima A, Jr. Fibroma of the vulva (Molluscum Pendulam). Obstet Gynecol Surv. $\quad 1952 \quad$ Dec;7(6):845-6. http://dx.doi.org/10.1097/00006254$\underline{195212000-00040}$

3. Chen DC, Chen $\mathrm{CH}$, Su HY, Yu CP, Chu TY. Huge pedunculated fibroma of the vulva. Acta Obstet Gynecol Scand. 2004 Nov;83(11):1091-2. PubMed PMID: 15488129. DOI: 10.1111/j.00016349.2004.0122b.x

4. Ajibona OO, Richards CJ, Davies Q. A distinctive vulval fibroma of so-called prepubertal type in a postmenopausal patient. J Clin Pathol. 2007 Apr;60(4):437-8. PubMed PMID: 17405983; PubMed Central PMCID: PMC2001108.

http://dx.doi.org/10.1136/jcp.2006.04042 $\underline{8}$ 